\title{
Fit in 50 years: participation in high school sports best predicts one's physical activity after Age 70
}

\author{
Simone Dohle ${ }^{1 *}$ and Brian Wansink ${ }^{2}$
}

\begin{abstract}
Background: The health benefits of physical activity are widely established, including decreased risk for disease and improved mental well-being. Yet many children, adolescents, and adults do not meet the minimum recommendations specified in current public health guidelines and physical activity is known to decrease during the life course. The aim of this study was to identify background or personality characteristics that predict whether a healthy 25 year-old would become a physically active 75 year-old. This could have powerful implications for targeting physical activity and health interventions.
\end{abstract}

Method: A unique data set was collected of 712 healthy United States males who passed a rigorous physical exam in the 1940s and who were surveyed 50 years later (in 2000). Their physical activity level after 50 years was correlated and regressed across a wide number of demographic, behavioral, and personality variables from when they were 50 years younger. Data was analyzed in 2012.

Results: In contrast to prior beliefs, self-rated personality profile as a young man had little predictive influence on later-life physical activity. Instead, the single strongest predictor of later-life physical activity was whether he played a varsity sport in high school, and this was also related to fewer self-reported visits to the doctor.

Conclusion: Encouraging systematic or frequent physical activity at a young age - whether through school sports or club opportunities - might be the best investment in long-term activeness. This is relevant at a time when funding for many sports programs is being eliminated and play time is being replaced with screen time.

Keywords: Exercise, Sports, Athletes, Retirement, Veterans, High school athletics, Football, Basketball, Baseball, Track, Elderly, Physical activity

\section{Background}

The health benefits of physical activity are widely established [1-3]. There is strong evidence that regular, moderate-intensity physical activity reduces the risk of coronary heart disease and stroke, diabetes, hypertension, colon cancer and breast cancer [1-3]. Moreover, research has shown that physical activity not only improves mental well-being, but also is effective treatment for clinical depression and anxiety $[4,5]$.

Despite the well-known positive effects of physical activity on various health outcomes, a broad range of evidence shows that many children, adolescents, and adults do not meet the minimum recommendations specified in current public health guidelines [6-10]. In addition, physical

\footnotetext{
* Correspondence: sdohle@ethz.ch

${ }^{1}$ Department of Health Science and Technology, Consumer Behavior, ETH

Zurich, Universitätsstrasse 22, CHN H75.3, 8092 Zurich, Switzerland

Full list of author information is available at the end of the article
}

activity is known to decrease during adolescence and adulthood, while sedentary behavior increases [6,11].

To develop effective environmental and policy interventions to increase physical activity in all ages, it is important to understand the correlates and determinants of physical activity and sedentary behavior [9,10,12-14]. For instance, the strongest environmental correlates of physical activity for children (aged 5-13 years depending on the study) have been shown to be walkability, traffic speed and volume, access and proximity to recreation facilities, residential density and land-use mix (i.e., proximity of homes and destinations such as shops) $[12,13]$. Residential density and land-use mix were also consistently associated with physical activity in adolescence (aged 12-18 depending on the study) [13]. Regarding psychosocial factors, research has shown that self-efficacy (confidence in the ability to be physically active in specific

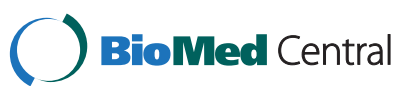


situations) is a consistent positive determinant of physical activity in children and adolescents $[10,12]$.

Fewer studies investigated how childhood and adolescence activity levels relate to adult activity levels (for a review, see [15]). In a non-concurrent prospective study of men in their mid-twenties, physical fitness test scores measured at both childhood and adolescent age levels were shown to predict physical activity levels as young adults [16]. Related studies point to a similar direction $[17,18]$. In contrast, however, other studies found that many individuals who were physically active as adolescents became relatively inactive as young adults [6] or showed that levels of physical activity in childhood and 20 years later were only weakly correlated $[19,20]$. Given these inconclusive findings, researchers have called for the need to identify potential moderators that may influence the tracking of physical activity $[6,15]$. While one set of these moderators is demographic - ethnicity, gender, or health status - another set of promising predictors might relate to one's background or personality.

Given the obesity trend, it is important to determine what predicts high - or low - activity levels in adulthood and old age. Not only does physical activity reduce risk of chronic disease and premature death, it also improves emotional, cognitive, social and psychological function in old age $[21,22]$. Consequently, it is a fundamental question if early physical activity levels influence physical activity in the elderly, also because such relationships are often presumed, but convincing data are lacking.

In a retrospective design, this research examines various long-term determinants of physical activity and health (i.e., self-reported visits to the physician). Taking into account several background, behavioral, and personality variables, the present study focuses on how young men's physical activity relates to activity and health in old age. In contrast to prior studies, it controls for baseline health status as a potential confounding variable by only including individuals who were markedly healthy as youths.

\section{Methods}

In the 1940s, the United States armed forces decided to screen potential servicemen to determine if they were "fit to fight" in World War II. At that time, malnutrition, physical infirmities or illiteracy precluded $47 \%^{\mathrm{a}}$ of the drafted or recruited population from serving [23]. Consequently, those who passed the physical exam were considered in top health. By limiting our sample to individuals who fit these two criteria - healthy and male - we hoped to reduce some of the variance that might have been endogenous to prior long-term panel and retrospective studies.

\section{Sample}

This study had approval from the University of Illinois IRB. In 2000, a random national sample of 7,500 World
War II veterans was asked to complete a questionnaire were asked to complete some background and personality questions regarding the time before and right after the war, and their current physical activity level. Of the 7,500 questionnaires that were initially mailed, 3,188 were undeliverable (often due to death or incapacitation). One thousand follow-up calls indicated that approximately $53 \%$ of the remaining non-respondents were individuals who had passed away, or who could not complete the survey because of health reasons (for details, see [24]). For the present study, only men who were physically healthy at the end of the war were included. Thus, it excludes females and veterans who received a purple heart for military merits, on the assumption that members of the latter group were wounded during the war. In addition, it only included those veterans from World War II who did not serve in any other conflict. The reason for this was that the World War II conscription system could be considered as a universal conscription; deferments were only approved for hardship cases or for those men who worked in the war industry or agriculture. Thus, the social background of men who served in World War II was similar to the non-serving cohort, except that the physical status of the soldiers was better than that of the civilian cohort [23]. This was not the necessarily the case for subsequent conflicts [23]. Deletion of cases which did not meet the inclusion criteria or with missing data on predictor or outcome variables yielded a final sample size of $N=712$. The mean age was $77.66(S D=2.34)$.

\section{Survey instrument}

Each veteran was sent the survey, a cover letter, and a business reply return envelope. The cover letter asked them to complete the survey. For their participation, a small donation was made in their name to the World War II Memorial. They were sent a copy of the major findings of the survey, and they were invited to a symposium that discussed the results.

Respondents were asked a wide range of background questions such as date of birth, how many years they were married to their first spouse, size of the town where they were raised, level of education, credit card use, and whether they were a member of a medical HMO. Some of the answers to the items were non-normal distributed or could not be interpreted directly; thus, they were dummycoded first. The question about marriage was used to calculate a dummy variable that was given a value of 1 if the respondent was married in 1946 and set to 0 otherwise. The question about size of the town where they were raised was coded into a dummy variable that was given a value of 1 if they responded if the town was larger than 10,000 people. Education was transformed into a dummy variable indicating if the respondent was a college graduate. Credit card use was used as proxy for income; the 
dummy-coded income variable was set to 1 if a respondent used his credit card more often than the median.

Another group of items related to behavioral variables such as whether they played high school varsity sports, and how many packs of cigarettes they smoked each month in 1946 (after the war was over). The question about smoking was recoded into three categories: nonsmokers, light smokers (up to 29 packs each month), and heavy smokers (30 or more packs per month).

To assess the personality variables, they were asked to indicate whether they possessed these traits $(1=$ strongly disagree; 9 = strongly agree) in 1946 (after the war). The personality traits comprised whether veterans considered themselves to be self-disciplined, to like routine, spontaneous, adventurous, comfortable taking risks, high self-worth, more dominant, restless, and self-centered.

While the use of the International or Global Physical Activity Questionnaire [12,25,26] would have been ideal, there was a concern that respondents would find it too lengthy or irrelevant for their age group. An alternative set of questions was asked and responses were aggregated into a scale. They were asked to indicate how many times on a typical month they (a) walk in the mall, (b) hunt in season, (c) fish in season, (d) golf in season, and (e) play sports; in addition, they were asked to indicate how many hours a week they spend (f) walking for exercise. Because most answers were highly skewed and transformation was unsuccessful, answers were dummy coded (with $0=$ "never does the activity" and $1=$ "does activity"). The sum of the answers to the six items was aggregated into a scale indicating the individual's current level of physical activity.

Finally, veterans were asked about their health. Respondents reported how many times they visited their physician in the past year. Because answers to this question were highly skewed, too, it was log-transformed before being analyzed.

\section{Results}

Data was analyzed in 2012. Significant univariate correlates of physical activity and visits to the physician are described in Table 1. Variables that were significantly related to physical activity were varsity sports and nonsmoking versus light smoking. Correlations were also noted between physical activity and personality variables (routine, spontaneous, adventurous, comfortable taking risks, dominant, and restless). Significant univariate correlates of visits to the physician were income, varsity sports, and non-smoking versus heavy smoking, but no univariate correlation was found between personality variables and visits to the physician.

Multiple linear regression analysis was used to determine the independent effects of the predictor variables on physical activity (see Table 2). Two variables showed a
Table 1 Correlates of future physical activity and physician visits

\begin{tabular}{lll}
\hline & $\begin{array}{l}\text { Physical } \\
\text { activity }\end{array}$ & $\begin{array}{l}\text { Visits to the } \\
\text { physician }\end{array}$ \\
\hline Age & .024 & .066 \\
Married & .004 & -.001 \\
Size town raised & .029 & .050 \\
College & -.024 & .013 \\
Income & .023 & $.128^{* *}$ \\
HMO member & -.047 & .014 \\
Varsity sports & $.164^{* *}$ & $-.085^{*}$ \\
Non-smoking vs. light smoking & $.082^{*}$ & -.053 \\
Non-smoking vs. heavy smoking & -.036 & $.115^{* *}$ \\
Self-disciplined & -.071 & .026 \\
Routine & $-.091^{*}$ & .051 \\
Spontaneous & $.077^{*}$ & .016 \\
Adventurous & $.169^{* *}$ & .067 \\
Comfortable taking risks & $.081^{*}$ & .016 \\
High self-worth & -.018 & .004 \\
More dominant & $.091^{*}$ & .052 \\
Restless & $.095^{*}$ & .019 \\
Self-centered & .068 & .017 \\
\hline P<.05* & &
\end{tabular}

${ }^{*} p<.05{ }^{* *} p<.01$. The Spearman rank correlation coefficient was used. Data collected in 2000 in the United States.

significant effect. Varsity sport was the strongest predictor $(\beta=0.173, p<.01)$. Men who played varsity sport in high school were more likely to be physically active in old age. In addition, respondents who were more adventurous were also more physically active $(\beta=0.164, p<.01)$.

The relative importance of the predictor variables to visits to the physician (log-transformed) was determined by a second multiple linear regression analysis. Table 3 gives an overview of the results of the analysis. In the multivariate regression, the largest predictor of visits to the physician was income: respondents with higher income went to the physician more often $(\beta=0.143, p<.01)$. Another significant predictor was smoking. Men who were heavy smokers in 1946 visited the doctor more often fifty years later than men who were non-smokers in $1946(\beta=$ $0.114, p<.01)$. Varsity sport was inversely related to visits to the physician; thus, men who played varsity sports visited the doctor less often $(\beta=-0.102, p<.01)$. A positive association was also found between age and visits to the physician $(\beta=0.100, p=.01)$. Finally, being adventurous was also a significant predictor, and positively related to visits to the physician $(\beta=0.119, p<.05)$.

\section{Discussion}

It is often presumed that physical activity and personality in childhood and adolescence predicts physical activity in 
Table 2 Multiple linear regression predicting physical activity

\begin{tabular}{|c|c|c|c|c|}
\hline & $B$ & $S E B$ & $\beta$ & $P$-value \\
\hline Constant & -.563 & 1.639 & & .732 \\
\hline \multicolumn{5}{|l|}{ Background } \\
\hline Age & .027 & .021 & .050 & .188 \\
\hline Married & .023 & .103 & .008 & .823 \\
\hline Size of town raised & .143 & .096 & .056 & .138 \\
\hline College education & -.100 & .100 & -.038 & .319 \\
\hline Income & .018 & .095 & .007 & .846 \\
\hline HMO member & -.157 & .099 & -.058 & .113 \\
\hline \multicolumn{5}{|l|}{ Behavioral } \\
\hline Varsity sport & .447 & .096 & .173 & $.001^{* *}$ \\
\hline \multicolumn{5}{|l|}{ Smoking } \\
\hline Non-smoking vs. light smoking & .186 & .122 & .062 & .127 \\
\hline Non-smoking vs. heavy smoking & -.058 & .109 & -.022 & .594 \\
\hline \multicolumn{5}{|l|}{ Personality } \\
\hline Self-disciplined & -.027 & .032 & -.038 & .400 \\
\hline Routine & -.043 & .024 & -.073 & .070 \\
\hline Spontaneous & .003 & .029 & .005 & .912 \\
\hline Adventurous & .100 & .029 & .164 & $.001^{* *}$ \\
\hline Comfortable taking risks & .002 & .028 & .003 & .945 \\
\hline High self-worth & -.027 & .032 & -.036 & .403 \\
\hline More dominant & .027 & .028 & .042 & .340 \\
\hline Restless & .020 & .023 & .035 & .387 \\
\hline Self-centered & .008 & .025 & .013 & .751 \\
\hline
\end{tabular}

**p $<.01$.

Adjusted $R^{2}=.06$.

Data collected in 2000 in the United States.

adulthood, or even old age. This research sought to more exactingly test the presumption that physical activity at a young age predicts physical activity at an elderly age. Importantly, this sample consisted of World War II veterans; therefore, it only included men who were in good health in their youth. This sample was representative of the entire age cohort, since the United States conscription system was fairly universal and inducted "...the chemist and the street cleaner, the physicist and the plumber, the biologist and the bookie" (Flynn, 1993, page 105).

These results revealed one critical youthful predictor of whether a man would be physically active after the age of 70: It was whether he participated in high school varsity sports. To our knowledge, no study has documented an influence of varsity sport on later physical activity over such a long time period, especially in a population that had already been prescreened as healthy, physically fit at a young age.

Despite the fact that recent studies found that environmental attributes are related to activity levels $[12,13]$ this study found no effect of the environment; the size of the
Table 3 Multiple linear regression predicting visits to the physician

\begin{tabular}{|c|c|c|c|c|}
\hline & $B$ & $S E B$ & $\beta$ & $P$-value \\
\hline Constant & -.437 & .433 & & .313 \\
\hline \multicolumn{5}{|l|}{ Background } \\
\hline Age & .014 & .005 & .100 & $.010^{*}$ \\
\hline Married & -.006 & .027 & -.009 & .813 \\
\hline Size of town raised & .014 & .025 & .021 & .571 \\
\hline College education & .009 & .026 & .013 & .728 \\
\hline Income & .096 & .025 & .143 & $.001^{* *}$ \\
\hline HMO member & .018 & .026 & .025 & .495 \\
\hline \multicolumn{5}{|l|}{ Behavioral } \\
\hline Varsity sport & -.069 & .025 & -.102 & $.007^{* *}$ \\
\hline \multicolumn{5}{|l|}{ Smoking } \\
\hline Non-smoking vs. light smoking & -.018 & .032 & -.023 & .569 \\
\hline Non-smoking vs. heavy smoking & .079 & .029 & .114 & $.006^{* *}$ \\
\hline \multicolumn{5}{|l|}{ Personality } \\
\hline Self-disciplined & -.002 & .008 & -.010 & .834 \\
\hline Routine & .009 & .006 & .058 & .155 \\
\hline Spontaneous & -.009 & .008 & -.051 & .247 \\
\hline Adventurous & .019 & .008 & .119 & $.014^{*}$ \\
\hline Comfortable taking risks & -.004 & .007 & -.022 & .616 \\
\hline High self-worth & -.007 & .009 & -.034 & .437 \\
\hline More dominant & .009 & .007 & .052 & .240 \\
\hline Restless & .001 & .006 & .007 & .859 \\
\hline Self-centered & -.001 & .007 & -.008 & .841 \\
\hline
\end{tabular}

town where a person was raised was not related to physical activity. Town size affects environmental attributes such as traffic speed and volume, or access and proximity to recreation facilities; it should be noted, however, that these attributes were not measured directly in the present study. Likewise, personality variables seem to have little bearing on physical activity in old age. Selfreported personality traits such as being adventurous, comfortable taking risks or being dominant showed some relation to physical activity in old age when considered in univariate analyses, but only being adventurous contributed a significant independent effect in the multivariate analysis.

The current study also shows that high school varsity sport is not only related to activity levels in old age, but also to health status in old age. Smoking as another behavioral variable also showed a strong influence on health. Individuals who were heavy smokers immediately after the war reported more frequent present-day doctor visits than non-smokers, pointing to the importance of public health interventions aimed to prevent smoking. 
Other predictors of long-term health were age, income, and again, being adventurous. It should be noted that being adventurous was positively related to visits to the doctor in old age, suggesting that being adventurous may foster physical activity, but probably also other, risky behaviors. Indeed, there is evidence that adventureseeking as part of a risk-taking personality is related to risky behavior, specifically to alcohol consumption and delinquency, and to a lesser extent, to drinking and driving, risky driving, and drug use [27]. Health practitioners or educators are therefore advised not to encourage overly adventurous behavior in adolescents.

\section{Limitations and future research}

Investigating the 50-year impact of different background, behavioral, and personality variables has methodological limitations. First, the design used retrospective questioning, which may involve selective recall or problems to retrieve information from memory [28,29]. In addition, while much research suggests that self-reported characteristics are quite stable throughout life [30], there may be biases in some of these measures [31]. For example, selfperception theory [32] states that people assume they possess certain characteristics by observing their own behavior. It could be that the men in this study simply inferred that they had certain characteristics. Further longitudinal research is warranted, using more extensive measures of personality as well as early life physical activity that allow differentiation between competitive sport and recreational physical activity.

It is also important to acknowledge that the present study is limited to healthy young men, and confounding by variables not controlled for cannot be completely excluded. A direction for further research is to delve deeper into the generalizability of the present results to other samples (e.g. females, less healthy populations).

\section{Conclusions}

These findings offer some compelling suggestions about how to target young adults at risk for long-term adult inactivity, chronic diseases, and premature death. In particular, these are youth who are not involved in organized sports (such as varsity athletics).

The first suggestion would be to maintain or enhance high school athletic programs, even in an era of shrinking school budgets. It has been noted that physical education classes may be the only opportunity for many adolescents to engage in weekly physical activity [33]. School-based organized sports should be preserved because they contribute to later physical activity levels and decrease the risk factors for early morbidity. Perhaps there are more cost-effective ways to maintain sports programs without eliminating them.
Second, it might be that other forms of relatively vigorous exercise and physical education classes could be promoted across grade levels. They need not concentrate on competition but rather on enjoyment, and on the benefits of and ways to stay physically active over the lifespan $[34,35]$. Finally, parents and other caregivers play a role in encouraging children to be active $[9,10,36,37]$ - including sports leagues and other exercises activities at youth centers, free or low-cost municipal summer camps, or YMCA's [34]. Less competitive children can be steered away from the more competitive sports and guided towards non-competitive forms of running, dance, swimming, weight lifting, or martial arts [34].

\section{Endnote}

a During World War II, the United States Selective Service System called up 19 million men. Nine million men were rejected because they didn't pass the double examination by local physicians and army induction centers [23].

Competing interests

The authors declare that they have no competing interests.

\section{Authors' contributions}

BW conceived of and conducted the study. SD analyzed and interpreted the data and drafted the manuscript. BW assisted in the interpretation of the data and provided critical feedback on drafts. SD and BW read and approved the final manuscript.

\section{Acknowledgements}

The authors are grateful to Julia Hastings-Black for editorial assistance.

\section{Author details}

'Department of Health Science and Technology, Consumer Behavior, ETH Zurich, Universitätsstrasse 22, CHN H75.3, 8092 Zurich, Switzerland. 2John S. Dyson Professor of Marketing at the Charles H. Dyson School of Applied Economics and Management, Cornell University, 15 Warren Hall, Ithaca, NY, USA.

Received: 7 March 2013 Accepted: 26 November 2013

Published: 1 December 2013

\section{References}

1. Hardman AE, Stensel DJ: Physical activity and health: the evidence explained. 2nd edition. London: Routledge; 2009.

2. Lee IM, Shiroma EJ, Lobelo F, Puska P, Blair SN, Katzmarzyk PT: Effect of physical inactivity on major non-communicable diseases worldwide: an analysis of burden of disease and life expectancy. Lancet 2012, 380(9838):219-229.

3. Bouchard C, Blair SN, Haskell WL: Physical activity and health. 2nd edition. Champaign, IL: Human Kinetics; 2012.

4. Fox KR: The influence of physical activity on mental well-being. Public Health Nutr 1999, 2(3a):411-418.

5. Lawlor DA, Hopker SW: The effectiveness of exercise as an intervention in the management of depression: systematic review and meta-regression analysis of randomised controlled trials. Brit Med J 2001, 322(7289):763-767.

6. Gordon-Larsen P, Nelson MC, Popkin BM: Longitudinal physical activity and sedentary behavior trends - adolescence to adulthood. Am J Prev Med 2004, 27(4):277-283.

7. Haskell WL, Lee IM, Pate RR, Powell KE, Blair SN, Franklin BA, Macera CA, Heath GW, Thompson PD, Bauman AE: Physical activity and public health: updated recommendation for adults from the American College of Sports Medicine and the American Heart Association. Med Sci Sports Exer 2007, 39(8):1423-1434. 
8. Pate RR, Pratt M, Blair SN, Haskell WL, Macera CA, Bouchard C, Buchner D, Ettinger W, Heath GW, King AC, et al: Physical activity and public health: a recommendation from the Centers for Disease Control and Prevention and the American College of Sports Medicine. J Am Med Assoc 1995, 273(5):402-407.

9. Sallis JF, Prochaska JJ, Taylor WC: A review of correlates of physical activity of children and adolescents. Med Sci Sport Exer 2000, 32(5):963-975.

10. van der Horst K, Paw MJCA, Twisk JWR, van Mechelen W: A brief review on correlates of physical activity and sedentariness in youth. Med Sci Sport Exer 2007, 39(8):1241-1250.

11. Kemper HC, Post GB, Twisk JW, van Mechelen W: Lifestyle and obesity in adolescence and young adulthood: results from the Amsterdam Growth And Health Longitudinal Study (AGAHLS). Int J Obes Relat Metab Disord 1999, 23(Suppl 3):S34-40

12. Bauman AE, Reis RS, Sallis JF, Wells JC, Loos RJF, Martin BW: Correlates of physical activity: why are some people physically active and others not? Lancet 2012, 380(9838):258-271.

13. Ding D, Sallis JF, Kerr J, Lee S, Rosenberg DE: Neighborhood environment and physical activity among youth: a review. Am J Prev Med 2011, 41(4):442-455

14. Uijtdewilligen L, Nauta J, Singh AS, van Mechelen W, Twisk JWR, van der Horst K, Chinapaw MJM: Determinants of physical activity and sedentary behaviour in young people: a review and quality synthesis of prospective studies. Brit J Sport Med 2011, 45(11):896-905.

15. Telama R: Tracking of physical activity from childhood to adulthood: a review. Obes Facts 2009, 2(3):187-195.

16. Dennison BA, Straus JH, Mellits ED, Charney E: Childhood physical fitness tests: predictor of adult physical activity levels? Pediatrics 1988, 82(3):324-330.

17. Curtis J, McTeer W, White P: Exploring effects of school sport experiences on sport participation in later life. Socio/ Sport J 1999, 16(4):348-365.

18. Raitakari OT, Porkka KV, Taimela S, Telama R, Rasanen L, Viikari JS: Effects of persistent physical activity and inactivity on coronary risk factors in children and young adults. The cardiovascular risk in young Finns study. Am J Epidemiol 1994, 140(3):195-205.

19. Cleland V, Dwyer T, Venn A: Which domains of childhood physical activity predict physical activity in adulthood? A 20-year prospective tracking study. Brit J Sport Med 2012, 46(8):595-602.

20. Telama R, Yang XL, Viikari J, Valimaki I, Wanne O, Raitakari O: Physical activity from childhood to adulthood - A 21-year tracking study. Am J Prev Med 2005, 28(3):267-273.

21. Taylor AH, Cable NT, Faulkner G, Hillsdon M, Narici M, Van der Bij AK. Physical activity and older adults: a review of health benefits and the effectiveness of interventions. J Sport Sci 2004, 22(8):703-725.

22. Warburton DER, Nicol CW, Bredin SSD: Health benefits of physical activity: the evidence. Can Med Assoc J 2006, 174(6):801-809.

23. Flynn GQ: The draft, 1940-1973. Lawrence, Kan: University Press of Kansas; 1993.

24. Wansink B, Payne $C R$, van Ittersum $K$ : Profiling the heroic leader: empirical lessons from combat-decorated veterans of World War II. Leadership Quart 2008, 19(5):547-555.

25. Bull FC, Maslin TS, Armstrong T: Global Physical Activity Questionnaire (GPAQ): nine country reliability and validity study. J Phys Act Health 2009, 6(6):790-804.

26. Craig $C L$, Marshall $A L$, Sjostrom $M$, Bauman $A E$, Booth $M L$, Ainsworth $B E$, Pratt M, Ekelund U, Yngve A, Sallis JF, et al: International physical activity questionnaire: 12-country reliability and validity. Med Sci Sport Exer 2003, 35(8):1381-1395.

27. Greene K, Krcmar M, Walters LH, Rubin DL, Hale JL: Targeting adolescent risk-taking behaviors: the contributions of egocentrism and sensation seeking. J Adolesc 2000, 23:439-461.

28. Bowling A: Research methods in health: investigating health and health services. 3rd edition. Maidenhead: Open University Press; 2009

29. Menard SW: Handbook of longitudinal research: design, measurement, and analysis. 1st edition. Amsterdam; London: Elsevier; 2008.

30. Costa P, McCrae R: Set like plaster? Evidence for the stability of adult personality. In Can personality change? Volume 21-40, edn. Edited by Heatherton F, Weinberger JL. Washington DC: American Psychological Association; 1994.
31. Bradburn NM, Wansink B, Sudman S: Asking questions: the definitive guide to questionnaire design, for market research, political polls, and social and health questionnaires. San Francisco, California: Jossey-Bass; 2004.

32. Bem DJ: Self-perception theory. In Advances in experimental socia psychology. Volume 6. Edited by Berkowitz L. New York: Academic Press; 1972:1-62.

33. Gordon-Larsen P, McMurray RG, Popkin BM: Determinants of adolescent physical activity and inactivity patterns. Pediatrics 2000, 105(6):e83.

34. Seiken2: Physical activity in children predicts adult health. http://seiken2. hubpages.com/hub/Physical-Activity-in-Children-Predicits-Adult-Health

35. Prochaska JJ, Sallis JF, Slymen DJ, McKenzie TL: A longitudinal study of children's enjoyment of physical education. Pediatr Exerc Sci 2003, 15(2):170-178

36. Yang $X$, Telama $R$, Leino $M$, Viikari J: Factors explaining the physical activity of young adults: the importance of early socialization. Scand Med Sci Sports 1999, 9(2):120-127.

37. Yang XL, Telama R, Laakso L: Parents' physical activity, socioeconomic status and education as predictors of physical activity and sport among children and youths-A 12-year follow-up study. Int Rev Sociol Sport 1996, 31(3):273-291.

doi:10.1186/1471-2458-13-1100

Cite this article as: Dohle and Wansink: Fit in 50 years: participation in high school sports best predicts one's physical activity after Age 70. BMC Public Health 2013 13:1100.

\section{Submit your next manuscript to BioMed Central and take full advantage of:}

- Convenient online submission

- Thorough peer review

- No space constraints or color figure charges

- Immediate publication on acceptance

- Inclusion in PubMed, CAS, Scopus and Google Scholar

- Research which is freely available for redistribution

Submit your manuscript at www.biomedcentral.com/submit
C Biomed Central 